\title{
What are emergency ambulance services doing to meet the needs of people who call frequently? A national survey of current practice in the United Kingdom
}

Helen A. Snooks ${ }^{1}$, Ashrafunnesa Khanom ${ }^{1 *}$ (D, Robert Cole ${ }^{2}$, Adrian Edwards ${ }^{3}$, Bethan Mair Edwards ${ }^{1}$, Bridie A. Evans ${ }^{1}$, Theresa Foster ${ }^{4}$, Rachael T. Fothergill ${ }^{5}$, Carol P. Gripper ${ }^{1}$, Chelsey Hampton ${ }^{1}$, Ann John ${ }^{1}$, Robin Petterson ${ }^{6}$, Alison Porter ${ }^{1}$, Andy Rosser ${ }^{2}$ and Jason $\mathrm{Scott}^{7}$

\begin{abstract}
Background: Emergency ambulance services are integral to providing a service for those with unplanned urgent and life-threatening health conditions. However, high use of the service by a small minority of patients is a concern. Our objectives were to describe: service-wide and local policies or pathways for people classified as Frequent Caller; call volume; and results of any audit or evaluation.

Method: We conducted a national survey of current practice in ambulance services in relation to the management of people who call the emergency ambulance service frequently using a structured questionnaire for completion by email and telephone interview. We analysed responses using a descriptive and thematic approach.

Results: Twelve of 13 UK ambulance services responded. Most services used nationally agreed definitions for 'Frequent Caller', with 600-900 people meeting this classification each month. Service-wide policies were in place, with local variations. Models of care varied from within-service care where calls are flagged in the call centre; contact made with callers; and their General Practitioner (GP) with an aim of discouraging further calls, to case management through cross-service, multi-disciplinary team meetings aiming to resolve callers' needs. Although data were available related to volume of calls and number of callers meeting the threshold for definition as Frequent Caller, no formal audits or evaluations were reported.
\end{abstract}

Conclusions: Ambulance services are under pressure to meet challenging response times for high acuity patients. Tensions are apparent in the provision of care to patients who have complex needs and call frequently. Multidisciplinary case management approaches may help to provide appropriate care, and reduce demand on emergency services. However, there is currently inadequate evidence to inform commissioning, policy or practice development.

Keywords: Emergency services, Calling frequently, Survey, Case management

\footnotetext{
* Correspondence: a.khanom@swansea.ac.uk

'Swansea University Medical School, Singleton Park, Swansea SA1 8PP, UK

Full list of author information is available at the end of the article
}

(c) The Author(s). 2019 Open Access This article is distributed under the terms of the Creative Commons Attribution 4.0 International License (http://creativecommons.org/licenses/by/4.0/), which permits unrestricted use, distribution, and reproduction in any medium, provided you give appropriate credit to the original author(s) and the source, provide a link to the Creative Commons license, and indicate if changes were made. The Creative Commons Public Domain Dedication waiver (http://creativecommons.org/publicdomain/zero/1.0/) applies to the data made available in this article, unless otherwise stated. 


\section{Background}

Demand on emergency ambulance services is growing at an unsustainable rate [1]. The volume of emergency calls to ambulance dispatch centres in England doubled from 4.72 million in $2001 / 02$, to 9 million in $2014 / 15$, presenting major operational challenges in a time of constrained spending on health care [2, 3]. Media attention and public concern are high [4]. Recent United Kingdom (UK) policy calls for a whole systems approach to care, with new care pathways and greater clinical autonomy within the ambulance service to reduce pressures on Emergency Departments (EDs) $[5,6]$.

While emergency services remain integral to providing a service for those with unplanned urgent and lifethreatening health conditions, high use of the service (includes calls to the ambulance service, EMS attendance or conveyance to ED) repeatedly by a minority of patients is a concern [7]. Their unresolved needs place pressure on the emergency ambulance service, which was designed to respond to patients with time-critical needs for clinical intervention, rather than to manage long-term care needs. Lack of pathways for referral and limited service availability, particularly out-of-hours, restrict the ability of ambulance personnel to direct patients to other services when appropriate. Patients may therefore attend ED, with lengthy waiting times and, potentially their needs can remain unresolved.

Definitions have varied and terminology is contested [7, 8] but UK ambulance services agreed in 2013 that people who make five or more calls per month or 12 calls over a three month period should be classified as 'Frequent Callers' [9]. In London alone, 1.7 million emergency calls were received in 2014-15. During this period 1622 people meeting the 'Frequent Caller' criteria generated 49,534 ambulance attendances, at a cost of $£ 4.4$ million to the London Ambulance Service (LAS) [1]. A similar story is repeated around the country $[10,11]$.

People who call the emergency ambulance service frequently may be experiencing falls, mental health problems, self-harming, misusing substances including alcohol, or living with chronic conditions. They are often vulnerable, lonely, living in poverty and experiencing a lower quality of life than the general population $[7,8$, 12-15].. Patients who make high use of emergency healthcare - in particular the ED - experience higher mortality rates than the general population [16].

In England, national policy [17] recognises the challenges of responding to patients who access the ED repeatedly, and commissioners now require ambulance services to have management strategies in place for people who call frequently [18, 19]. International evidence indicates improved patient care and service delivery where case management is used in emergency care settings [20]. Some preliminary research on case management for this patient group in the UK reported significant reductions in calling following the introduction of case management in one area of London, although the sample size was small $(n=110)$ and the study design was an uncontrolled before and after comparison [7]. However, the extent and nature of services adopted across the UK's ambulance service regions is currently unknown.

In this paper we present results of a national survey of current practice in relation to the management of people who call the ambulance service frequently. Our objectives were to describe: service-wide and local policies or pathways; numbers of people classified as Frequent Caller; and results of any audit or evaluation.

\section{Methods \\ Design}

Survey study using a structured questionnaire for completion by email and supplemented by telephone interviews. All participants firstly emailed their consent to participate in telephone interviews and also provided verbal consent prior to the interview taking place. This study did not require ethical approval from the NHS Health Research Authority (HRA) or Swansea University ethics committee. We used the HRA decision tool to determine need for ethics approval.

\section{Setting}

UK ambulance services are funded centrally by the National Health Service consisting of services in England $(n=10)$, Wales $(n=1)$, Scotland $(n=1)$ and Northern Ireland $(n=1)$. Each ambulance service covers a wide geographical region, with separate commissioning arrangements within those service areas, totalling 218 groups responsible for commissioning services. Services commissioned within each local area include primary care, planned hospital care, rehabilitative care, urgent and emergency care (including out-of-hours), community health, mental health and learning disability services.

Ambulance services provide 999 emergency ambulances, rapid response vehicles, First Responders and patient transport services. Ambulance vehicles are required to carry a wide range of equipment including intravenous drips, drugs, oxygen and heart defibrillators. All services are expected to meet national performance targets to improve response times. Most air ambulance services in the UK are not part of the NHS and are funded through charitable donations.

Ambulance service staff are trained to a very high level, which enables them to deal with any aspect of emergency care, from minor injuries to cardiac arrest, or multiple casualties sustained in serious road traffic accidents. Ambulance crews typically include an emergency 
care assistant and a paramedic or an advanced paramedic practitioner.

\section{Data collection and participants}

The questionnaire included open questions related to policies and pathways that were in place across the service and any local variations. We asked for details about who was involved in any cross-service partnerships or Multi-Disciplinary Team (MDT) meetings. We also asked about the volume of calls classified as Frequent Caller and whether the service had undertaken any audit or evaluation. We contacted the designated 'Frequent Caller' leads at all 13 UK ambulance services by email initially, with telephone follow up to complete the survey and clarify emailed responses (AK, $\mathrm{CH}$ ).

\section{Analysis}

We analysed responses (HS and $\mathrm{AK}$ ) using a descriptive and inductive thematic approach [21] to data analysis where theoretical perspectives are informed by the interpretation of raw data. HS and AK read through the survey responses several times searching for reported commonalities and differences between services and systematically coded the data to draw out themes and categories to illustrate emerging concepts. Through discussion, these themes and categories were further refined and clustered into codes and sub-codes concerning policies and volume, care provision, perceived causes of high use and resources available.

\section{Research team}

The team had multi-disciplinary and specialist input including paramedics, ambulance service managers, social care managers, public health and primary care clinicians, patients and methodologists. Patients worked alongside stakeholder and academic partners to oversee conduct of this work, consider implications of survey findings and how they could inform an application for further research $[22,23]$.

\section{Results}

\section{Response rate}

We received email and telephone responses from 12 of 13 UK ambulance services. Five ambulance services responded to our emailed survey questions, however we were able to collate a more detailed response from all 12 services through follow-up telephone calls. We received no response to our emails from one service.

We report on four themes identified from our analysis of the survey data. These include policies and volume; care provision; perceived causes of high use and resources available.

\section{Policies and volume}

Most respondents $(n=10)$ reported that a service-wide policy was in place, with all services using the nationally agreed criteria for 'Frequent Caller' classification and compiling a list of patients meeting this definition. These callers are flagged on the electronic ambulance dispatch system so that subsequent calls are identified. Some services provided data about the scale of the problem ranging from 600 to 900 patients included on lists each month. Although each service held data on patients, there was little reported in the way of formal audit or evaluation. Two services reported that they were taking no specific actions in relation to this patient group. Responses are summarised in Table 1.

\section{Care provision}

In many areas, service-wide policy was to contact the person who has reached the threshold of the Frequent Caller classification, usually by letter. In the letter the patient is encouraged to contact their General Practitioner (GP) to try to address their healthcare problems. The GP is also alerted to the classification of one of their patients as a Frequent Caller. A care plan may be written within the ambulance service, for use in the ambulance dispatch centre. In this case, any further calls are triaged and may be passed to a clinician in the dispatch centre for advice over the telephone, with referral to other services if appropriate and available. Anti-social behaviour arrangements may be put in place (services 4,8 ). Two services reported that home visits may be made by an ambulance service operational or clinical manager with an appropriate health care professional e.g. mental health, drugs and alcohol service or the police (services $4,8)$. Service 4 described the drafting of a 12 month 'Acceptable Behaviour Contract' by the multi-disciplinary team, for sharing with the caller during a home visit. "Inappropriate use of services" would be discussed during that visit. In this service "if all other measures failed" a "restricted send" policy could be put into place - to only send an ambulance in the case of a life-threatening condition. An escalation option was also reported by service 4, of referral to the police for action to be taken under the Misuse of Communications Act 2003 [24]. Monitoring of safeguarding issues was reported by one service (9). The explicit aim of these 'within-service' models was described as discouraging further calling, and to manage further calls without the dispatch of an emergency ambulance.

Despite reporting service-wide policy, nine services reported also having local cross-service multi-disciplinary initiatives in some areas (example presented in Box 1). Nine services reported that they had implemented crosssector multi-disciplinary case management models in at least one area (services 1,2,3,4,5,6,8,9,10), with one 
Table 1 A summary of responses to a UK wide survey of ambulance service current policies and practice in relation to the management of the care of people who make frequent emergency calls

\begin{tabular}{llll}
\hline Service & Service-wide policy & Local policies/pathways & Call volume \\
\hline 1 & Service wide policy in place & One area of service has an initiative & Not reported \\
& National definitions for 'Frequent & which started in 2015 & No audit or evaluation reported; \\
Caller' used & Aim - to identify triggers which lead & Frequent Caller lead reviews cases \\
Aim - to discourage people from & to the patient making the call e.g. & on four monthly basis
\end{tabular}
calling

$2 \quad$ Service wide policy updated 2017 National Definitions for 'Frequent Caller' used

Aim - to reduce further calls to emergency ambulance service

3 Service wide policy in place National definitions for Frequent Caller used

Aim - to close cases (take the person off the frequent caller list) and reduce calls National definitions for 'Frequent Caller' used

Aim- to reduce or prevent people from calling

$5 \quad$ Service wide developed policy developed in 2017

National definitions for Frequent Caller used

No specific aim reported

$6 \quad$ Service wide policy in place since 2013, currently being updated National definitions for 'Frequent Caller' used No specific aim reported

$7 \quad$ Service wide policy in place National definitions for 'Frequent Caller' used

Aim - to reduce calls and address reasons for calling Actions for callers meeting defined threshold

$8 \quad$ Service wide policy since 2007 National definitions for 'Frequent Caller' used No explicit aim given

$9 \quad$ Service wide policy since 2013 National definitions for 'Frequent Caller' used No specific aim given

$10 \quad$ Service wide policy since 2009 National definitions for 'Frequent Caller' used Aim - to reduce calls and ED attendance

adverse childhood events, mental

health, drug and alcohol dependency

One area of ambulance service has initiative started in 2017.

Aim - to work together to ascertain

any unmet needs with a view to reducing demand

Several areas participate in MDT meetings.

No specific aim given

346 patients on active management plans at time of response

600 patients a month team involved with 50 callers per month

In several areas cross service initiatives are in place.

Aim - to work as a multi-agency team

to reduce demand and provide the patient with the most appropriate care to meet their complex needs

In one area cross-service initiative started in 2017

No specific aim reported

Additional programme in one area targeted at patients with mental

health problems - started in 2016

No specific aim reported

No variations reported by area

Several areas have cross service initiatives in place

Aim - to ensure that patients have access to the most appropriate care pathway. Usually callers have an exacerbation of an underlying chronic illness over a short period of time and do not know which service to access; or they have recently left hospital (geriatric) or prison; have a mental health condition; have recently experienced a bereavement or have a drug or alcohol problem

In one area a service has been set up which uses the GP neighbourhood model Aim - to identify why patients are calling and see what support can be put in place to support them

One area has a new pilot service which started in 2017

Aim - to reduce calls and reduce ED

attendance

900 people per month are classified as

'Frequent Caller'

200 calls per month

No data provided Frequent Caller per year

No data given
No figures given

700 calls per month

Auditing at individual case level, in process of developing evaluation process on larger scale

None reported

No audit or evaluation undertaken

No audit or evaluation reported

No audit or evaluation reported

2500 people classified as No audit or evaluation reported

No audit or evaluation reported

Pilot schemes audited on monthly basis

No audit or evaluation reported 
Table 1 A summary of responses to a UK wide survey of ambulance service current policies and practice in relation to the management of the care of people who make frequent emergency calls (Continued)

\begin{tabular}{llll}
\hline Service & Service-wide policy & Local policies/pathways & Call volume
\end{tabular}

reporting that case management was in place across the entire service area (service 7). Case management models varied locally, in some cases being available only to a subgroup of the population e.g. 'persistent' or 'non-engaged' callers (services $3,4,10$ ) or callers with mental health problems (services 6,10). Multi-disciplinary case management meetings had varied attendance, but typically included clinical and operational representatives from: Ambulance service, Emergency Department, primary care, Community Mental Health Trust, Community matron/District nurse service, Clinical Commissioning Group, Social services, housing department, Fire Service, Police, Patient Advocacy Services/ voluntary sector, and Occupational Therapy services. Patients may be invited to attend these meetings to discuss their issues with care providers across some services (services 1,4), whilst other services may hold meetings to discuss patient needs in their absence (service 2). Some multi-disciplinary meetings were chaired and hosted by the ambulance services (service 3); and in other cases the ambulance service representative attended the meeting, which may include planning the care of patients who make high use of other services such as the emergency department (services 2,5). Within the case management approach two services (services 8 , 10) reported visiting patients at home whenever possible to better understand their needs. Service 10 reported carrying out home visits to undertake a holistic assessment of needs; with provision of equipment, support to attend appointments, medication reviews and referral to other agencies as available options to try to meet patients' needs and reduce further emergency responses from the ambulance service.

\section{Perceived causes of high use}

Services reported that sometimes people make high use of the emergency ambulance service in a period of change or crisis e.g. exacerbation of underlying chronic illness, following discharge from hospital, recent bereavement or release from prison. Service 8 reported that most calls arose when patients did not know how to access appropriate services, and that in some cases contact with the patient, identification of underlying issues and discussions or referral may resolve the immediate problem of frequently calling the emergency ambulance service.

\section{Resources available}

In some cases one or more Clinical Support Officers or the Frequent Caller lead (usually paramedic) were allocated to work on resolving these cases (services 1,2,6,9); in other services this work was undertaken by local operations managers (services $3,4,5$ ) or a mixed team (services 7,10). In one service National Health Service (NHS) 111, a telephone based $24 \mathrm{~h}$ health information and advice line, managed this caseload (9). In three services resources for tackling this workload were not clearly reported (services 8,12,13).

Box 1 Example of variation between areas within one service

\begin{tabular}{|c|c|}
\hline Service-wide policy & Local cross-service multi-disciplinary initiative \\
\hline $\begin{array}{l}\text { Aim - to discourage people classified as Frequent Caller from further } \\
\text { calling } \\
\text { Actions for callers meeting defined threshold: } \\
\text { - Clinical Support Officer (CSO) contacts patient by letter stating they } \\
\text { have called the emergency ambulance service more than normal and } \\
\text { should seek help from their GP, contact number provided within letter } \\
\text { for patient to talk to ambulance service manager; and calls or sends } \\
\text { letter to GP to make them aware patient is calling the emergency } \\
\text { ambulance service frequently } \\
\text { - If calls persist, CSO may contact other services to intervene and } \\
\text { support patient } \\
\text { - CSO writes individual care plan which is shared with the call centre } \\
\text { clinical team. When the patient calls (s) he is triaged to a clinician in the } \\
\text { call centre rather than sending an ambulance } \\
\text { - If caller persists then (s) he may be referred to the police and court }\end{array}$ & $\begin{array}{l}\text { Aim - to identify triggers which lead to the patient making the call e.g. } \\
\text { adverse childhood events, mental health, drug and alcohol dependency } \\
\text { Actions for callers meeting defined threshold: } \\
\text { - CSO speaks to GP or practice manager first } \\
\text { - Patient is discussed at monthly MDT meeting. Around } 50 \text { patients may } \\
\text { be discussed at one meeting, 10-15 of these making high use of } \\
\text { ambulance service. MDT is used to provide a network of support for the } \\
\text { patient and to address their needs through multi-agency working. Pro- } \\
\text { fessionals see it as part of their role to support people who frequently } \\
\text { access the ambulance service, police or ED. Agencies involved: police, } \\
\text { ED, Out of Hours primary care, voluntary sector, social services } \\
\text { - Patient allocated to appropriate agency to lead on care planning and } \\
\text { provision. A care plan is created and shared so that any agency } \\
\text { contacted by the patient knows what has been agreed } \\
\text { - Patient interviewed individually to assess need } \\
\text { - If calls persist or patient has an anti-social behaviour order, the CSO visits } \\
\text { the patient along with a police officer or representative from the ED }\end{array}$ \\
\hline
\end{tabular}




\section{Discussion}

\section{Summary of findings}

The management of people who make frequent calls to ambulance services is a priority for UK ambulance services, supported by national and local policy. All responding ambulance services had a designated 'Frequent Caller' lead and kept data about calls made by people classified as Frequent Callers, using nationally agreed definitions. Models of care for these patients varied widely between and within services, from 'withinservice' flagging and efforts to discourage further calls to partnership working across services through multidisciplinary team meetings in a case management approach. Although data were available related to volume of calls and number of callers meeting the threshold for definition as Frequent Caller, no formal audits or evaluations were reported.

\section{Limitations}

We achieved a high response rate, although very little detail was provided by two devolved nations within the UK, and one regional service did not respond at all. We are unaware of any differences between responding and non-responding services in terms of the management of the care of people who call frequently. We used a semistructured survey approach with responses by email or telephone. Detail varied by respondent and there were inconsistencies in responses provided.

\section{Implications}

Tension is apparent between management of this caseload to reduce pressure on the ambulance service and management of these callers in response to their needs. In some cases the processes for managing the care of people who call frequently were led by staff in operational management roles, in others care was clearly within the remit of clinical members of staff. The aims of the services reflected this tension. Where the response was primarily 'within-service', aims tended to focus on reducing calls, with an emphasis on managing the behaviour of people making high use of the emergency ambulance service. Referral of callers to the police for anti-social behaviour management or prosecution was reported as an option. By contrast, the cross-service partnerships used a 'case management' type model, seeking to resolve callers' clinical, social or emotional needs. Reflecting this tension, multi-disciplinary teams included clinicians, health service managers, voluntary sector representatives and the police.

Previous research has shown that people who frequently call emergency ambulance services may be vulnerable and unable to access more appropriate services, such as primary care $[5,8,11-14]$. They appear to seek help through this route because other available services do not meet their complex needs, particularly during evenings and weekends. However, the emergency ambulance route to help-seeking may often be unsuccessful and inefficient, for them individually and for the NHS. It has potential consequences also for other patients who do not get the speedy response required when in urgent need, as resources are tied up with patients who may not need acute care. There is a conflict between the time required for appropriate assessment, onward referral, management planning and operational pressures of emergency work. Services are being pressured by commissioners to reduce times spent on scene and to reduce conveyance to ED, again reflecting the tensions inherent in provision of care to patients with complex needs. Over the longer term these policies and pulls should work together if effective, but in the short term there may be increased on-scene times which can be regarded as an additional burden on the emergency care service. Multidisciplinary case management approaches with strong emergency ambulance service involvement may reduce demand on emergency services and emergency hospital admissions because people are effectively treated [25-27].

\section{Future research}

The introduction of case management has potential to achieve safe and equitable out-of-hospital care for patients who call the emergency ambulance service frequently, whilst avoiding shifting patients to another part of the emergency care system without their needs being met. However, additional research is required to determine whether case management is effective in practice in this setting [20, 28]. The recently funded quasiexperimental STRETCHED study (National Institute of Health Research (NIHR) HS\&DR 180302) investigates the effectiveness of case management approaches for people who make high use of the emergency ambulance service. We will investigate what helps case management to work, and what hinders the implementation and effective functioning of this model.

Results of the STRETCHED evaluation will inform policy and practice to support people who make high use of the emergency ambulance service. Many services have implemented case management approaches in at least one area, but with limited evidence of effectiveness of efficiency.

\section{Conclusions}

Ambulance services are under pressure to meet challenging response times for high acuity patients. Tensions are apparent in the provision of care to patients who have complex needs and call frequently. Within service care focused mainly on reducing calls whilst multidisciplinary case management aimed to resolve clinical and emotional needs of patients. However, there is currently inadequate evidence to inform commissioning, policy or practice development. 


\section{Abbreviations}

AK: Ashrafunnesa Khanom; CH: Chelsey Hampton; CSO: Clinical Support Officer; ED: Emergency Department; GP: General Practice; HS: Helen Snooks; MDT: Multi-Disciplinary Team; NHS: National Health Service; NIHR: National Institute of Health Research; UK: United Kingdom

\section{Acknowledgements}

We would like to express our gratitude to the ambulance services 'Frequent Caller' leads for participating in this study. We would also like to thank the ambulance services Frequent Caller National Network (FReCANN) and the ambulance services Research and Development Leads for supporting the study.

\section{Authors' contributions}

HS conceived the study concept and design and developed the survey questions with $A K$ and with the advice of all co-authors $A E, B A E, C P G, C H, T F$, $B M E, A J, J S, A R, A P, R C, R T F, R P$. AK identified the 'Frequent Caller' leads from all 13 ambulance services. AK and $\mathrm{CH}$ collected survey data through emails and telephone interviews. HS and AK analysed and interpreted the survey responses. HS drafted the manuscript. All co-authors reviewed the manuscript and responded with comments. All approved the final manuscript.

\section{Funding}

This work was supported by PRIME Centre Wales, funded as part of the Health and Care Research Wales research infrastructure in primary and emergency care research. The funders had no role in study design, data collection and analysis, decision to publish or preparation of the manuscript.

\section{Availability of data and materials}

The data that support the findings of this study are available from the corresponding author upon reasonable request.

\section{Ethics approval and consent to participate}

This study did not require ethical approval from the NHS Health Research Authority (HRA) or Swansea University ethics committee. We used the HRA decision tool to determine need for ethics approval. All participants firstly emailed their consent to participate in telephone interviews and also provided verbal consent prior to the interview taking place.

\section{Consent for publication}

Not applicable.

\section{Competing interests}

The authors declare that they have no competing interests.

\section{Author details}

${ }^{1}$ Swansea University Medical School, Singleton Park, Swansea SA1 8PP, UK. ${ }^{2}$ West Midlands Ambulance Service, Trust Headquarters, Millennium Point, Waterfront Business Park, Waterfront Way, Brierley Hill, West Midlands DY5 1LX, UK. ${ }^{3}$ Division of Population Medicine School of Medicine, Cardiff University, Cardiff CF10 3AT, UK. ${ }^{4}$ East of England Ambulance Service, Bury St Edmunds, Suffolk, UK. ${ }^{5}$ London Ambulance Service, 220 Waterloo Rd, Lambeth, London SE1 8SD, UK. ${ }^{6}$ Welsh Ambulance Services NHS Trust Headquarters, Ty Elwy, Unit 7, Ffordd Richard Davies, St Asaph Business Park, St Asaph, Denbighshire LL17 OLJ, UK. ${ }^{7}$ Northumbria University, Sutherland Building, Newcastle-upon-Tyne NE1 8ST, England.

Received: 5 November 2019 Accepted: 17 December 2019 Published online: 28 December 2019

\section{References}

1. The Health and Social Care Information Centre (HSCIC). Ambulance services, England 2014-15. Available from: http://content.digital.nhs. uk/catalogue/PUB17722/ambu-serv-eng-2014-2015-rep.pdf. Accessed 21.6 .19

2. Association of ambulance chief executives. Annual Report 2014-15. Available from: http://aace.org.uk/wp-content/uploads/2015/10/AACEANNUAL-REPORT-2014-2015-FINAL-W.pdf. Accessed 18.6.19.

3. Keogh B, Urgent and Emergency Care Review Team. Transforming urgent and emergency care services in England Urgent and Emergency Care Review End of Phase 1 Report. Leeds: NHS England; 2013.
4. Ambulance target failures highlight NHS crisis, say health chiefs. Available from: https://www.the guardian.com/society/2016/nov/30/ ambulance-target-failures-health-chiefs-says-problem-system-wide/ Accessed 18.6.19.

5. Department of Health. Taking healthcare to the patient. Transforming NHS ambulance services, 2005. Available from: http://ircp.info/ Portals/11/Future/NHS\%20EMS\%20Policy\%20Recommendation2005.pdf. Accessed 18.6.19.

6. The NHS Long Term Plan 2019. Available from: https://www.longtermplan. nhs.uk/wp-content/uploads/2019/01/nhs-long-term-plan-june-2019.pdf. Accessed 19.7.19.

7. Edwards MJ, Bassett G, Sinden L, Fothergill RT. Frequent callers to the ambulance service: patient profiling and impact of case management on patient utilisation of the ambulance service. Emerg Med J 2014; Oct 13.

8. Scott J, Strickland AP, Warner K, Dawson P. Frequent callers to and users of emergency medical systems: a systematic review. Emerg Med J. 2014;31(8):684-91.

9. London Ambulance Service. Caring for frequent callers https://www. londonambulance.nhs.uk/health-professionals/caring-frequent-callers/

10. NHS England. Ambulance Quality Indicators; April 2017. Available from: https:// www.england.nhs.uk/statistics/statistical-work-areas/ambulance-qualityindicators/ambulance-quality-indicators-data-2017-18/ Accessed 1.6.19.

11. Ambulance Quality Indicators by area and month; January 2019. Available from: https://statswales.gov.wales/Catalogue/Health-and-Social-Care/NHSPerformance/Ambulance-Services/ambulancequalityindicators-by-lhb-month Accessed 1.6.19.

12. Scott J, Strickland AP, Warner K, Dawson P. Describing and predicting frequent callers to an ambulance service: analysis of 1 year call data. Emerg Med J. 2014:31(5):408-14.

13. Agarwal G, Lee J, McLeod B, Mahmuda S, Howard M, Cockrell K, et al. Social factors in frequent callers: a description of isolation, poverty and quality of life in those calling emergency medical services frequently. Scandinavian journal of trauma, resuscitation and emergency medicine. BMC Public Health. 2019;19:684.

14. Søvsø MB, Kløjgaard TA, Hansen PA, Christensen EF. Repeated ambulance use is associated with chronic diseases-a population-based historic cohort study of patients' symptoms and diagnoses. Scand J Trauma Resusc Emerg Med. 2019; Dec;27(1):46.

15. Kuek BJW, Li H, Yap S, Ng MXR, Ng YY, White AE, et al. Characteristics of frequent users of emergency medical Services in Singapore. Prehosp Emerg Care. 2018:1-10. https://doi.org/10.1080/10903127.2018.1484969.

16. Moe J, Kirkland S, Ospina MB, Campbell S, Long R, Davidson A, et al. Mortality, admission rates and outpatient use among frequent users of emergency departments: a systematic review. Emerg Med J. 2016; Mar;33(3): 230-6. https://doi.org/10.1136/emermed-2014-204496.

17. Stevens S. Five year forward view. London: NHS England; 2014

18. Welsh Ambulance Service NHS Trust. The Performance Report 2017-2018. Available from: http://www.ambulance.wales.nhs.uk/assets/documents/3748ad3 9-486e-4fa2-bec3-d2a84e50e9b9636688214339037291.pdf Accessed 1.7.19.

19. Smith D. Frequent caller: identification and management policy. North west ambulance service NHS trust; 2015. Available from: https://www.nwas.nhs. uk/media/387174/frequent_callers_policy final_v2 0 ds.pdf.

20. Hudon C, Chouinard M-C, Lambert M, Dufour I, Krieg C. Effectiveness of case management interventions for frequent users of healthcare services: a scoping review. BMJ Open. 2016;6(9).

21. Braun V, Clarke V, Hayfield N, Terry G. Thematic analysis. In: Handbook of Research Methods in Health Social Sciences; 2018. p. 1-8.

22. Evans BA, Bedson $E$, Bell $P$, Hutchings $H$, Lowes $L$, Rea $D$, et al. Involving service users in trials: developing a standard operating procedure. Trials. 2013;14:219.

23. Staniszewska S, Brett J, Simera I, Seers K, Mockford C, Goodlad S. GRIPP2 reporting checklists: tools to improve reporting of patient and public involvement in research. BMJ. 2017;358:j3453.

24. The National Archives. Misuse of Communication Act 2003. Available from: http://www.legislation.gov.uk/uksi/2010/2291/contents/made Accessed 21.6.19.

25. Mercer T, Bae J, Kipnes J, Velazquez M, Thomas S, Setji N. The highest utilizers of care: individualized care plans to coordinate care, improve healthcare service utilization, and reduce costs at an academic tertiary care center. J Hosp Med. 2015:10(7):419-24.

26. Hansagi H, Olsson M, Hussain A, Ohlén G. Is information sharing between the emergency department and primary care useful to the care of frequent emergency department users? Eur J Emerg Med. 2008;1:34-9. 
27. Wassmer RW, Winward L, Derlet R. Does Counseling Reduce Frequent Emergency Department Use? Rochester: Social Science Research Network; 2008. Report No.ID 1093870. Available from: https://papers.ssrn.com/ abstract=1093870 Accessed 21.6.19

28. Scott J. Delivering clinical case management for frequent callers to ambulance services. Emerg Med J. 2015;35(5):342. https://doi.org/10.1136/ emermed-2014-204354.

\section{Publisher's Note}

Springer Nature remains neutral with regard to jurisdictional claims in published maps and institutional affiliations.

Ready to submit your research? Choose BMC and benefit from:

- fast, convenient online submission

- thorough peer review by experienced researchers in your field

- rapid publication on acceptance

- support for research data, including large and complex data types

- gold Open Access which fosters wider collaboration and increased citations

- maximum visibility for your research: over $100 \mathrm{M}$ website views per year

At BMC, research is always in progress.

Learn more biomedcentral.com/submissions 